\title{
Degree of Glomerulosclerosis in Procurement Kidney Biopsies from Marginal Donor Kidneys and Their Implications in Predicting Graft Outcomes
}

\author{
Wisit Cheungpasitporn ${ }^{1, *} \mathbb{1}$, Charat Thongprayoon ${ }^{2, *}$, Pradeep K Vaitla ${ }^{1}\left(\mathbb{D}\right.$, Api Chewcharat ${ }^{2}$, \\ Panupong Hansrivijit ${ }^{3}$, Felicitas L. Koller ${ }^{4}$, Michael A Mao ${ }^{5}{ }^{\circledR}$, Tarun Bathini ${ }^{6}$, \\ Sohail Abdul Salim ${ }^{1}$, Sreelatha Katari ${ }^{7}$, Lee S Cummings ${ }^{7}$, Eddie Island ${ }^{7}$, Jameson Forster ${ }^{7}$ \\ and Napat Leeaphorn ${ }^{7, *}$ \\ 1 Division of Nephrology, Department of Medicine, University of Mississippi Medical Center, \\ Jackson, MS 39216, USA; pvaitla@umc.edu (P.K.V.); sohail3553@gmail.com (S.A.S.) \\ 2 Division of Nephrology and Hypertension, Mayo Clinic, Rochester, MN 55905, USA; \\ chewcharat.api@mayo.edu \\ 3 Department of Internal Medicine, University of Pittsburgh Medical Center Pinnacle, \\ Harrisburg, PA 17105, USA; hansrivijitp@upmc.edu \\ 4 Department of Transplant and Hepatobiliary Surgery, University of Mississippi Medical Center, \\ Jackson, MS 39216, USA; fkoller@umc.edu \\ 5 Division of Nephrology, Division of Nephrology and Hypertension, Mayo Clinic, \\ Jacksonville, FL 32224, USA; mao.michael@mayo.edu \\ 6 Department of Internal Medicine, University of Arizona, Tucson, AZ 85721, USA; tarunjacobb@gmail.com \\ 7 Renal Transplant Program, School of Medicine/Saint Luke's Health System, University of Missouri-Kansas \\ City, Kansas City, MO 64110, USA; skatari@saint-lukes.org (S.K.); lscummings@saint-lukes.org (L.S.C.); \\ eisland@saint-lukes.org (E.I.); jforster@saint-lukes.org (J.F.) \\ * Correspondence: wcheungpasitporn@gmail.com (W.C.); charat.thongprayoon@gmail.com (C.T.); \\ napat.leeaphorn@gmail.com (N.L.)
}

\begin{abstract}
Background: This study aimed to assess the association between the percentage of glomerulosclerosis (GS) in procurement allograft biopsies from high-risk deceased donor and graft outcomes in kidney transplant recipients. Methods: The UNOS database was used to identify deceased-donor kidneys with a kidney donor profile index (KDPI) score $>85 \%$ from 2005 to 2014. Deceased donor kidneys were categorized based on the percentage of GS: $0-10 \%, 11-20 \%,>20 \%$ and no biopsy performed. The outcome included death-censored graft survival, patient survival, rate of delayed graft function, and 1-year acute rejection. Results: Of 22,006 kidneys, $91.2 \%$ were biopsied showing 0-10\% GS (58.0\%), $11-20 \%$ GS $(13.5 \%)$, > $20 \%$ GS $(19.7 \%)$; $8.8 \%$ were not biopsied. The rate of kidney discard was $48.5 \%$; $33.6 \%$ in $0-10 \%$ GS, $68.9 \%$ in $11-20 \%$ GS, and $77.4 \%$ in $>20 \%$ GS. $49.8 \%$ of kidneys were discarded in those that were not biopsied. Death-censored graft survival at 5 years was $75.8 \%$ for $0-10 \%$ GS, $70.9 \%$ for $>10 \%$ GS, and $74.8 \%$ for the no biopsy group. Among kidneys with $>10 \%$ GS, there was no significant difference in death-censored graft survival between $11-20 \%$ GS and $>20 \%$ GS. Recipients with $>10 \%$ GS had an increased risk of graft failure (HR $=1.27, p<0.001$ ), compared with $0-10 \%$ GS. There was no significant difference in patient survival, acute rejection at 1-year, and delayed graft function between $0 \%$ and $10 \%$ GS and $>10 \%$ GS. Conclusion: In $>85 \%$ KDPI kidneys, our study suggested that discard rates increased with higher percentages of GS, and GS $>10 \%$ is an independent prognostic factor for graft failure. Due to organ shortage, future studies are needed to identify strategies to use these marginal kidneys safely and improve outcomes.
\end{abstract}

Keywords: procurement kidney biopsy; glomerulosclerosis; kidney transplantation; transplantation; outcomes 


\section{Introduction}

In the United States, more than 90,000 patients with end-stage kidney disease (ESKD) are currently waiting for a kidney transplant [1,2]. A significant gap between the number of kidney transplant candidates and donors remains an ongoing problem, resulting in a median wait time exceeding four years [3-6]. This delay has a dramatic impact on ESKD patients on the transplant waiting list, as their survival is, on average, below $40 \%$ after 5 years on dialysis [7]. Despite the severe organ shortage, a significant number of procured organs are discarded every year [8,9].

The shortage of deceased donor organs continues to be a problem in kidney transplantation despite the implementation of expanded criteria donor (ECD) programs in 2002 to increase the use of organs from donors with $\geq 60$ years or comorbidities [10]. In 2013, the United Network of Organ Sharing (UNOS) Kidney Transplantation Committee approved a new allocation policy based on the kidney donor profile index (KDPI), a percentile score that compares an organ to previously recovered kidneys and signifies donor factors affecting transplant function [11]. KDPI $>85 \%$ kidneys, previously designated as expanded criteria donor (ECD) kidneys, are offered to patients who have consented to accept a non-ideal renal allograft, thereby increasing access to earlier kidney transplantation [11]. Unfortunately, the discard rate for KDPI $>85 \%$ kidneys continues to be high, close to $50 \%$ under the new kidney allocation system (KAS). The major determinants of discarded kidneys are donor comorbidities and procurement wedge biopsy findings, especially the percentage of glomerulosclerosis (GS) [8,12-16].

Despite conflicting evidence regarding the prognostic capability of histologic findings for differentiating donor kidneys at greater risk of inferior outcomes [17-19], the use of procurement biopsies has become an increasingly common practice, particularly in KDPI $>85 \%$ kidneys in which $95 \%$ of recovered kidneys were biopsied $[9,18,20]$. The percentage of GS is commonly the primary biopsy information reviewed because it provides a convenient cutoff for offer turndowns $[8,21,22]$. This is in spite of studies noting that the percentage of GS has failed to consistently predict graft outcomes [18,21,23-29].

The aim of this study is to explore the association between the percentage of GS and graft outcomes in kidney transplant recipients who received KDPI >85\% kidneys between 1 January 2005 to 2 December 2014 using the Organ Procurement and Transplantation Network (OPTN)/UNOS database.

\section{Methods}

\subsection{Data Source and Study Population}

We used the OPTN/UNOS database to identify deceased-donor kidneys recovered from January 1, 2005 to December 2, 2014 (before implementation of the kidney allocation system). The study was exempt from the institutional review board due to the publicly available nature of the de-identified database of the OPTN/UNOS database. All data used in the analysis were provided by UNOS through the Standard Transplant Analysis and Research (STAR) database. The database is a de-identified, patient-level data source that contains donor, waitlist, and transplant recipient variables derived from UNet forms for any transplant in the United States after October 1, 1987. KDPI (reference year of 2017) was calculated based on donor factors to summarize the likelihood of graft failure after deceased donor kidney transplant. Higher KDPI scores are associated with shorter estimated graft function. Although the KDPI was not formally introduced into allocation policy until implementation of the new kidney allocation system (KAS) on December 2014, the OPTN/UNOS database has KDPI values for $99 \%$ of all deceased donor recipients who underwent kidney transplantation during the study period. To assess the predictive value of procurement biopsy GS percentage in high-risk deceased donors, we only included deceased-donor kidneys with a KDPI score $>85 \%$. We excluded recovered kidneys for dual-kidney transplant and kidneys from donors with body weight $<20 \mathrm{~kg}$. Subsequently, we assess the post-transplant outcomes based on GS percentage in deceased-donor kidney transplant recipients who received kidney with KDPI $>85 \%$. We excluded patients undergoing kidney re-transplants or multi-organ transplant from the analysis. 


\subsection{Outcomes}

We categorized deceased donor kidneys into four groups based on the percentage of GS: $0-10 \%$, $11-20 \%,>20 \%$ and no biopsy performed. We investigated the kidney discard rates and post-transplant deceased donor allograft outcomes based on GS groups. The primary outcome was death-censored graft survival. Death-censored graft survival began at kidney transplant, was followed until graft failure, defined as the requirement of renal replacement therapy and/or kidney re-transplant, and was censored at death or the end of study (6 September 2018), whichever was earlier. The secondary outcomes were patient survival, rate of delayed graft function, and 1-year acute rejection. Delayed graft function was defined as a requirement of dialysis within the first week of transplantation. As there was no statistical difference in any post-transplant outcomes between $11-20 \%$ and $>20 \%$ GS (Table S1), we combined these two groups together ( $>10 \%$ GS) when assessing post-transplant outcomes.

\subsection{Covariates}

Donor-related factors included donor age, sex, race, diabetes mellitus, hypertension, body mass index, the last serum creatinine before kidney procurement, donation after cardiac death, hepatitis $\mathrm{C}$ virus (HCV) antibody status, cause of death, and machine perfusion. Recipient-related factors included recipient age, sex, race, body mass index, diabetes mellitus, preemptive transplant, dialysis duration, and panel reactive antibody. Transplant-related factors included HLA-DR mismatch, cold ischemic time, transplant period, and induction therapy.

\subsection{Statistical Analysis}

Baseline characteristics were described using mean \pm standard deviation (SD) for continuous variables or frequencies with percentage for categorical variables. Continuous variables were compared between GS groups using the student's $t$-test or ANOVA, as appropriate. Categorical variables were compared between GS groups using the Chi-squared test. Patient survival and death-censored graft survival outcomes were estimated using the Kaplan-Meier method with significance tested using the log-rank test. The associations of the GS percentage group with death-censored graft failure and patient mortality was assessed using Cox proportional hazards analysis. The proportional hazards assumption was tested using Schoenfeld residuals $(p=0.29)$. Because the OPTN/UNOS database did not specify the date of occurrence, the associations of the GS percentage group with delayed graft function and 1-year acute rejection were assessed using logistic regression analysis. Multivariable analysis was performed to adjust for covariates associated with outcomes of interest with $p<0.05$ in univariate analysis. All $p$-values were two-tailed, and $p$-values of $<0.05$ were considered significant. Stata version 13 (StataCorp, College Station, TX, USA) was used for all statistical analyses.

\section{Results}

\subsection{Kidney Procurement Cohort and Rate of Kidney Discard}

During the study period, 25,154 kidneys were recovered from deceased donors with KDPI > 85\%. A total of 3014 kidneys recovered for dual-kidney transplant and 134 kidneys from donors with a body weight $<20 \mathrm{~kg}$ were excluded. A total of 22,006 kidneys with KDPI $>85 \%$ were included in the kidney procurement cohort. Of these kidneys, $58.0 \%$ had $0-10 \%$ GS, $13.5 \%$ had $11-20 \%$ GS, $19.7 \%$ had $>20 \%$ GS, and $8.8 \%$ had no kidney biopsy performed (Figure S1). Overall, the rate of kidney discard was $48.5 \% ; 33.6 \%$ in $0-10 \%$ GS, $68.9 \%$ in $11-20 \%$ GS, and $77.4 \%$ in $>20 \%$ GS. $49.8 \%$ kidneys were discarded in the no kidney biopsy group.

\subsection{Kidney Transplant Recipient Cohort}

In this cohort of 22,006 deceased donor kidneys with KDPI > 85\%, 10,662 kidneys were discarded. After excluding 1032 recipients with prior kidney transplants or undergoing multi-organ transplant, 
a total of 10,312 recipients with donor KDPI $>85 \%$ were included in the post-transplant outcome analysis. Of these patients, $75.6 \%$ had $0-10 \%$ GS, $11.9 \%$ had $11-20 \%$ GS, $4.9 \%$ had $>20 \%$ GS, and $7.6 \%$ had no kidney biopsy performed (Figure S2). The median (IQR) number of glomeruli in each kidney biopsy was 47 (IQR: 28, 69). There was no association between KDPI and percent of GS ( $p=0.70)$. The donor, recipient, and transplant-related characteristics stratified by percent of GS are shown in Table 1.

Table 1. Characteristics of donors, recipients, and transplant according to percent GS in transplanted allograft.

\begin{tabular}{|c|c|c|c|c|c|}
\hline & \multicolumn{5}{|c|}{ Glomerulosclerosis } \\
\hline & $0-10 \%$ & $11-20 \%$ & $>20 \%$ & No-Biopsy & $p$-Value \\
\hline$N$ & 7796 & 1230 & 500 & 786 & \\
\hline \multicolumn{6}{|l|}{ Donor } \\
\hline Age (years) & $60.7 \pm 7.1$ & $60.5 \pm 6.9$ & $60.6 \pm 6.7$ & $58.5 \pm 7.4$ & $<0.001$ \\
\hline Male (\%) & 46.7 & 41.1 & 46.4 & 36.6 & $<0.001$ \\
\hline Black (\%) & 28.8 & 29.5 & 25.2 & 30.0 & 0.26 \\
\hline Diabetes (\%) & 26.5 & 34.2 & 30.6 & 20.2 & $<0.001$ \\
\hline Hypertension (\%) & 79.0 & 81.8 & 80.8 & 73.8 & $<0.001$ \\
\hline BMI $\left(\mathrm{kg} / \mathrm{m}^{2}\right)$ & $28.8 \pm 6.9$ & $29.2 \pm 7.5$ & $29.2 \pm 7.5$ & $27.3 \pm 6.5$ & $<0.001$ \\
\hline Creatinine $(\mathrm{mg} / \mathrm{dL})$ before kidney procurement & $1.2 \pm 1.0$ & $1.2 \pm 0.6$ & $1.2 \pm 0.5$ & $1.2 \pm 1.0$ & 0.04 \\
\hline Donor after cardiac death (\%) & 10.0 & 7.1 & 6.8 & 4.6 & $<0.001$ \\
\hline HCV antibody positive (\%) & 5.8 & 2.4 & 2.8 & 12.9 & $<0.001$ \\
\hline \multicolumn{6}{|l|}{ Cause of death $(\%)$} \\
\hline Cerebrovascular accident & 78.1 & 79.4 & 83.0 & 82.8 & 0.002 \\
\hline Machine perfusion (\%) & 49.9 & 51.2 & 47.8 & 19.5 & $<0.001$ \\
\hline Expanded criteria donor (\%) & 85.4 & 87.7 & 86.4 & 75.5 & $<0.001$ \\
\hline \multicolumn{6}{|l|}{ Recipient } \\
\hline Age (years) & $61.5 \pm 9.8$ & $62.4 \pm 9.6$ & $61.6 \pm 9.8$ & $59.9 \pm 10.6$ & 0.001 \\
\hline Male $(\%)$ & 64.0 & 63.1 & 63.2 & 63.9 & 0.92 \\
\hline Black (\%) & 36.4 & 36.8 & 40.6 & 33.3 & 0.07 \\
\hline BMI & $27.9 \pm 5.3$ & $28.4 \pm 5.5$ & $27.5 \pm 5.0$ & $27.6 \pm 5.4$ & 0.001 \\
\hline Diabetes (\%) & 47.2 & 46.8 & 48.8 & 47.1 & 0.90 \\
\hline \multicolumn{6}{|l|}{ Dialysis duration (\%) } \\
\hline Preemptive & 9.8 & 8.9 & 9.8 & 9.0 & 0.70 \\
\hline$<1$ years & 8.7 & 8.1 & 7.0 & 9.5 & 0.41 \\
\hline $1-3$ years & 29.6 & 26.7 & 30.8 & 30.7 & 0.13 \\
\hline$>3$ years & 49.4 & 54.0 & 48.4 & 46.8 & 0.006 \\
\hline \multicolumn{6}{|l|}{ PRA (\%) } \\
\hline$<10$ & 81.7 & 84.7 & 81.8 & 78.1 & 0.003 \\
\hline $10-60$ & 12.0 & 9.8 & 12.6 & 15.0 & 0.005 \\
\hline$>60$ & 5.9 & 4.6 & 4.4 & 5.7 & 0.21 \\
\hline Missing & 0.5 & 0.9 & 1.2 & 1.2 & 0.01 \\
\hline \multicolumn{6}{|l|}{ Transplant } \\
\hline \multicolumn{6}{|l|}{ HLA DR mismatch (\%) } \\
\hline 0 & 8.2 & 7.2 & 7.8 & 8.9 & 0.42 \\
\hline 1 & 39.0 & 36.3 & 38.4 & 36.9 & 0.27 \\
\hline 2 & 52.8 & 56.5 & 53.8 & 54.2 & 0.12 \\
\hline Cold ischemic time (hours) & $19.5 \pm 9.4$ & $20.5 \pm 9.5$ & $19.8 \pm 9.1$ & $15.7 \pm 9.2$ & $<0.001$ \\
\hline \multicolumn{6}{|l|}{ Transplant period } \\
\hline 2005-2007 & 28.6 & 22.7 & 35.0 & 45.2 & $<0.001$ \\
\hline $2008-2010$ & 33.8 & 31.6 & 35.6 & 27.4 & 0.001 \\
\hline $2011-2014$ & 37.6 & 45.7 & 29.4 & 27.5 & $<0.001$ \\
\hline \multicolumn{6}{|l|}{ Induction therapy (\%) } \\
\hline Thymoglobulin & 46.1 & 52.3 & 51.4 & 47.3 & $<0.001$ \\
\hline Alemtuzumab & 14.7 & 13.5 & 16.0 & 9.5 & 0.001 \\
\hline Basiliximab & 18.9 & 19.2 & 17.2 & 24.7 & 0.001 \\
\hline Other induction & 7.6 & 8.1 & 5.2 & 7.1 & 0.19 \\
\hline No induction & 16.3 & 11.0 & 13.4 & 15.0 & $<0.001$ \\
\hline
\end{tabular}

GS, glomerulosclerosis; HCV, hepatitis C virus; BMI, body mass index; PRA, panel reactive antibody; HLA, human leukocyte antigen.

\subsection{Baseline Characteristics Based on Percentages of Glomerulosclerosis}

Table 2 summarizes and compares donor, recipient, and transplant-related characteristics between $0-10 \%$ and $>10 \%$ GS allograft groups. Kidneys donors with $>10 \%$ GS had a higher prevalence of female 
sex, diabetes and hypertension. Kidney donors with 0-10\% GS had a higher prevalence of donation after cardiac death and positive hepatitis $C$ antibody. Recipients of kidneys with GS $>10 \%$ were older and had longer dialysis vintage, whereas recipients of kidneys with 0-10\% GS had higher panel reactive antibodies. Kidney transplants with $>10 \%$ GS had more HLA DR mismatch, cold ischemic time, and thymoglobulin induction. Kidney transplants with $0-10 \%$ GS had more transplants without induction therapy.

Table 2. Comparison of donors, recipients, and transplant characteristics between GS 0-10\% and GS > $10 \%$ transplanted allografts.

\begin{tabular}{|c|c|c|c|}
\hline & \multicolumn{3}{|c|}{ Glomerulosclerosis } \\
\hline & $\mathbf{0 - 1 0 \%}$ & $>10 \%$ & $p$-Value \\
\hline$N$ & 7796 & 1730 & \\
\hline \multicolumn{4}{|l|}{ Donor } \\
\hline Age (years) & $60.7 \pm 7.1$ & $60.5 \pm 6.8$ & 0.18 \\
\hline Male (\%) & 46.7 & 42.7 & 0.002 \\
\hline Black (\%) & 28.8 & 28.3 & 0.66 \\
\hline Diabetes (\%) & 26.5 & 33.1 & $<0.001$ \\
\hline Hypertension (\%) & 79.0 & 81.5 & 0.02 \\
\hline BMI $\left(\mathrm{kg} / \mathrm{m}^{2}\right)$ & $28.8 \pm 6.9$ & $29.2 \pm 7.5$ & 0.04 \\
\hline Creatinine $(\mathrm{mg} / \mathrm{dL})$ before kidney procurement & $1.2 \pm 1.0$ & $1.2 \pm 0.6$ & 0.85 \\
\hline Donor after cardiac death (\%) & 10.0 & 7.0 & $<0.001$ \\
\hline HCV antibody positive (\%) & 5.8 & 2.5 & $<0.001$ \\
\hline \multicolumn{4}{|l|}{ Cause of death $(\%)$} \\
\hline Cerebrovascular accident & 78.1 & 80.4 & 0.04 \\
\hline Machine perfusion (\%) & 49.9 & 50.2 & 0.82 \\
\hline Expanded criteria donor (\%) & 85.4 & 87.3 & 0.04 \\
\hline \multicolumn{4}{|l|}{ Recipient } \\
\hline Age (years) & $61.5 \pm 9.8$ & $62.2 \pm 9.6$ & 0.003 \\
\hline Male (\%) & 64.0 & 63.1 & 0.48 \\
\hline Black $(\%)$ & 36.4 & 37.9 & 0.26 \\
\hline BMI & $27.9 \pm 5.3$ & $28.1 \pm 5.4$ & 0.35 \\
\hline Diabetes (\%) & 47.2 & 47.4 & 0.86 \\
\hline \multicolumn{4}{|l|}{ Dialysis duration $(\%)$} \\
\hline Preemptive & 9.8 & 9.1 & 0.40 \\
\hline$<1$ years & 8.7 & 7.8 & 0.25 \\
\hline $1-3$ years & 29.6 & 27.9 & 0.16 \\
\hline$>3$ years & 49.4 & 52.4 & 0.02 \\
\hline \multicolumn{4}{|l|}{ PRA $(\%)$} \\
\hline$<10$ & 81.7 & 83.9 & 0.03 \\
\hline $10-60$ & 12.0 & 10.6 & 0.10 \\
\hline$>60$ & 5.9 & 4.6 & 0.03 \\
\hline Missing & 0.5 & 1.0 & 0.01 \\
\hline \multicolumn{4}{|l|}{ Transplant } \\
\hline \multicolumn{4}{|l|}{ HLA DR mismatch (\%) } \\
\hline 0 & 8.2 & 7.4 & 0.30 \\
\hline 1 & 39.0 & 36.9 & 0.10 \\
\hline 2 & 52.8 & 55.7 & 0.03 \\
\hline Cold ischemic time (hours) & $19.5 \pm 9.4$ & $20.3 \pm 9.4$ & $<0.001$ \\
\hline \multicolumn{4}{|l|}{ Transplant period } \\
\hline 2005-2007 & 28.6 & 26.2 & 0.05 \\
\hline 2008-2010 & 33.8 & 32.8 & 0.40 \\
\hline $2011-2014$ & 37.6 & 41.0 & 0.008 \\
\hline \multicolumn{4}{|l|}{ Induction therapy (\%) } \\
\hline Thymoglobulin & 46.1 & 52.0 & $<0.001$ \\
\hline Alemtuzumab & 14.7 & 14.2 & 0.59 \\
\hline Basiliximab & 18.9 & 18.6 & 0.79 \\
\hline Other induction & 7.6 & 7.3 & 0.67 \\
\hline No induction & 16.3 & 11.7 & $<0.001$ \\
\hline
\end{tabular}

GS, glomerulosclerosis; HCV, hepatitis C virus; BMI, body mass index; PRA, panel reactive antibody; HLA, human leukocyte antigen. 


\subsection{Post-Transplant Outcomes Based on Percentages of Glomerulosclerosis}

The median (IQR) follow-up was $4.87(2.90,7.02)$ years after kidney transplant. During follow-up, $3015(29.2 \%)$ patients had allograft failure, and 4433 (43.0\%) patients died. A total of $1443(14.0 \%)$ patients had acute rejection within one year, and 3436 (33.3\%) patients had delayed graft function. Figure 1 compares death-censored graft survival between $0-10 \%$ and $>10 \%$ GS. Graft survival rate at 5 years was $75.8 \%$ for $0-10 \%$ GS and $70.9 \%$ for $>10 \%$ GS $(p<0.001)$.

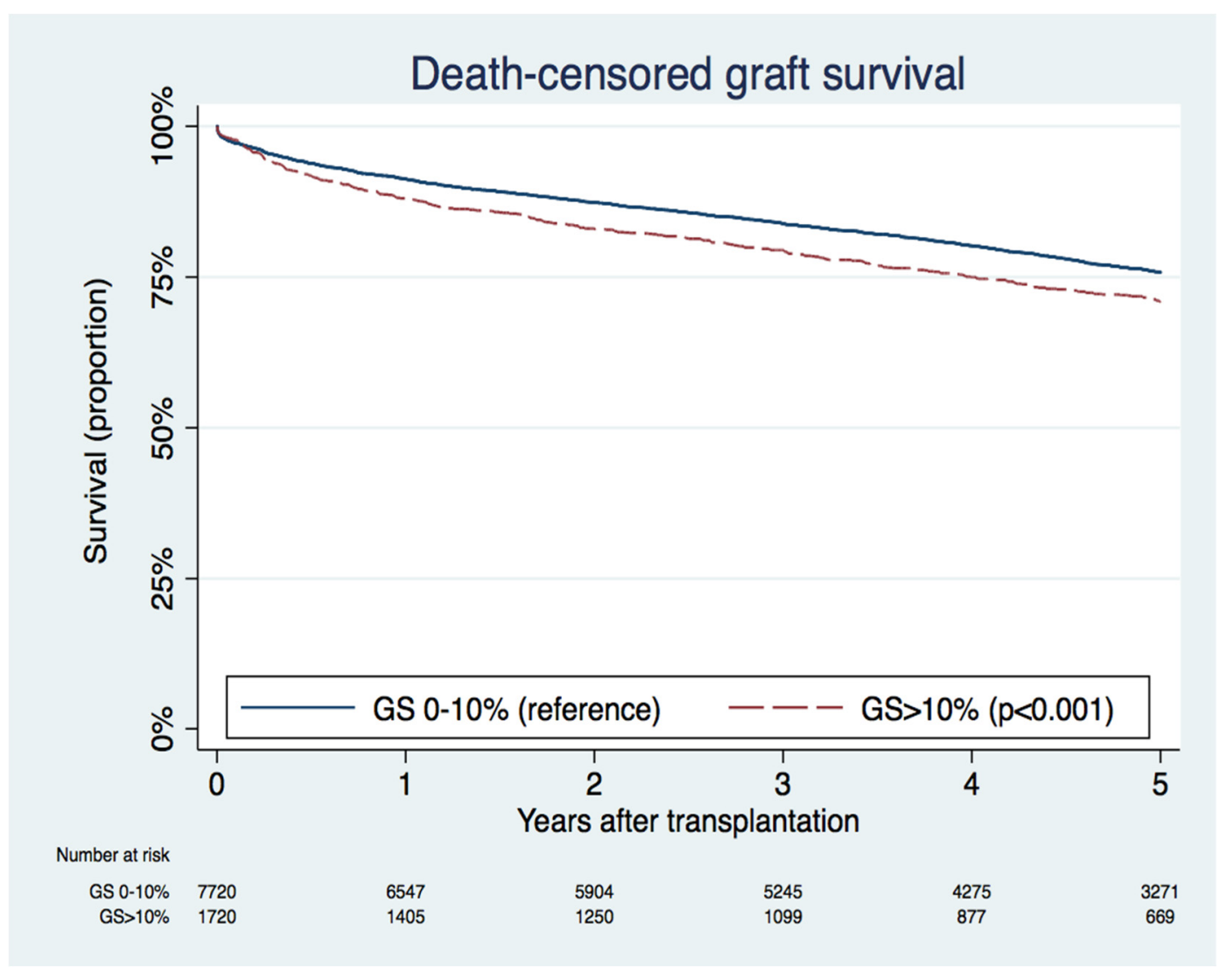

Figure 1. Kaplan-Meier death-censored graft survival curves between $0-10 \%$ and $>10 \%$ allograft glomerulosclerosis (GS) groups.

In unadjusted analysis, kidneys with $>10 \%$ GS were associated with a $24 \%$ higher risk of graft failure compared to kidneys with $0-10 \%$ GS (HR 1.24; $95 \%$ CI 1.13-1.36, $p<0.001$ ). After adjusting for baseline donor, recipient, and transplant-related factors, kidneys with $>10 \%$ GS remained significantly associated with a $27 \%$ higher risk of graft failure compared to kidneys with $0-10 \%$ GS (HR 1.27; $95 \%$ CI 1.15-1.40, $p<0.001$ ) (Table S2). Of note, there was no difference in death-censored graft survival between 11-20\% GS and $>20 \%$ GS (Figure 2 and Table S1). There was no significant difference in patient survival (HR 1.03; 95\% CI 0.96-1.12, $p=0.40$ ), rate of acute rejection at 1-year (HR 1.13; 95\% CI $0.97-1.31, p=0.11$ ), and rate of delayed graft function (HR 1.10; 95\% CI 0.98-1.23, $p=0.11$ ) between $0-10 \%$ GS and $>10 \%$ GS (Table S2).

We examined the graft outcomes of $>85 \%$ KDPI kidney with a low degree of GS, compared with $71-85 \%$ KDPI kidneys. The death-censored graft survival at 5 years in $>85 \%$ KDPI kidneys with $0-10 \%$ GS was inferior to in $71-85 \%$ KPDI kidneys $(75.8 \%$ vs. $81.2 \%$; $p<0.001)$, as shown in Figure 3.

\subsection{Characteristics and Outcomes of Kidneys with No Biopsy Performed}

Kidneys donors with no biopsy performed were younger, more were female, and had a greater prevalence of positive hepatitis C antibody, but had a lower prevalence of diabetes, hypertension, 
body weight, donation after cardiac death, use of machine perfusion, and expanded criteria donation when compared with kidneys with $0-10 \%$ GS (Table 1 ). Graft survival rate at 5 years was comparable between $0 \%$ and $10 \%$ GS and the no biopsy group $(75.8 \%$ vs. $74.8 \% ; p=0.62)$, as shown in Figure 2 .

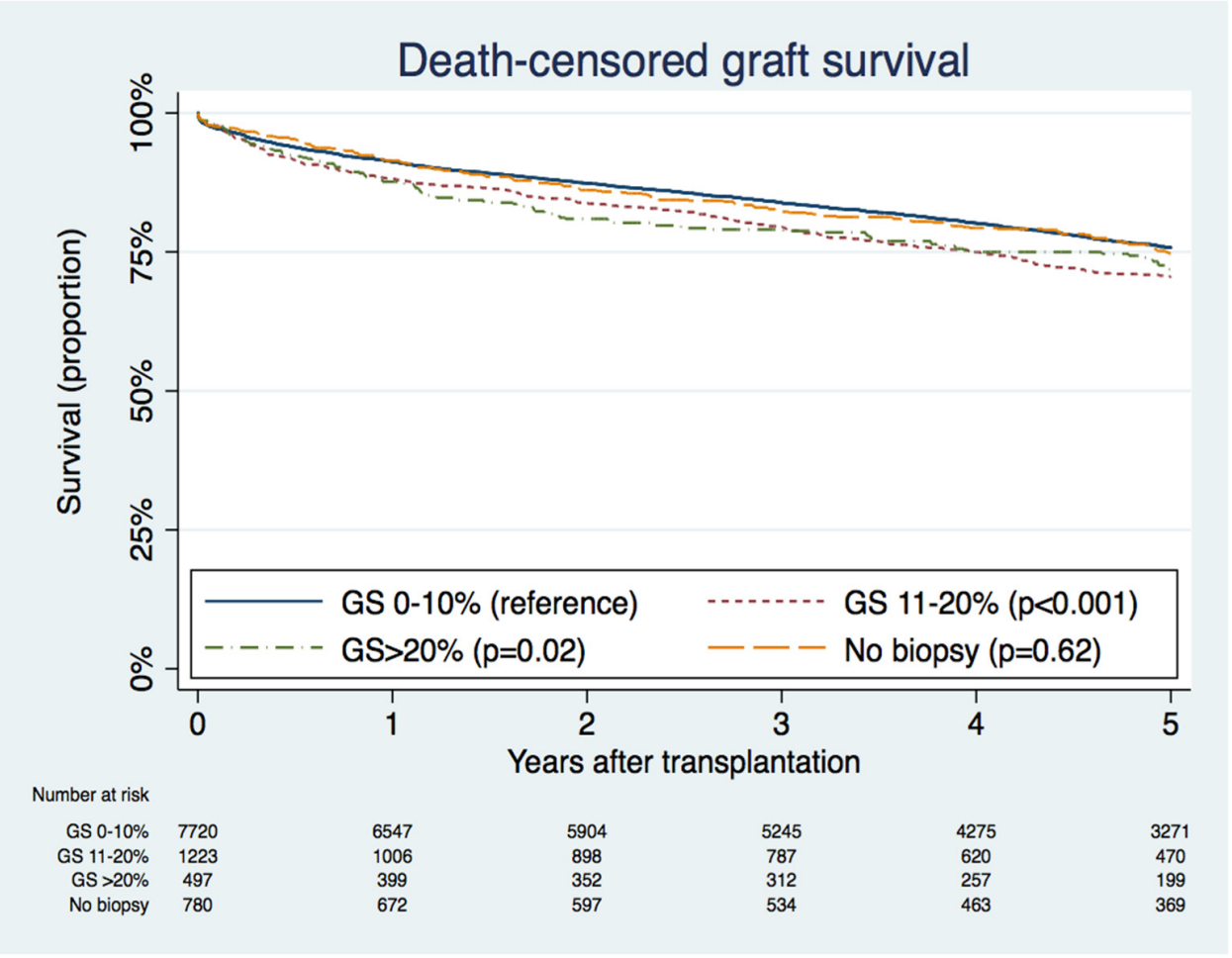

Figure 2. Kaplan-Meier death-censored graft survival curves according to percent glomerulosclerosis (GS) in allografts.

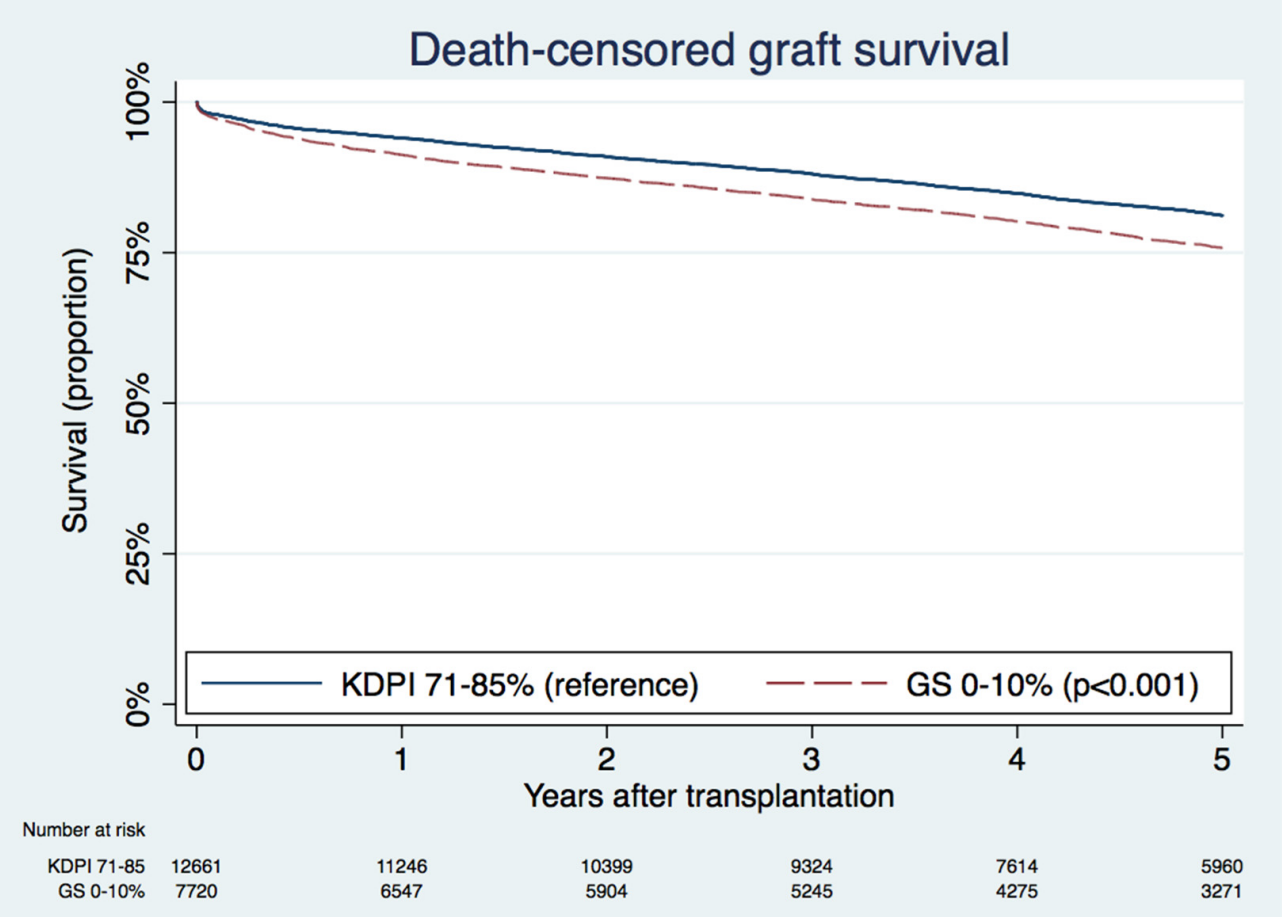

Figure 3. Kaplan-Meier death-censored graft survival curves between the kidney donor profile index (KDPI) $71-85 \%$ group and the KDPI > 85\% with 0-10\% percent glomerulosclerosis (GS) group. 


\section{Discussion}

Over 700,000 patients in the United States have ESKD, with the United States having the secondhighest incidence rate of treated ESKD in the world [30]. Despite an improvement in dialysis care over the last 15 years, the overall survival on dialysis remains dismal with $22 \%$ at one year, $43 \%$ at three years and $58 \%$ at five years [31]. The risk of death is reduced by up to $66 \%$ with kidney transplantation [31]. A major limitation to increasing the number of kidney transplantations is the number of donors. It is thus of paramount importance to decrease the discard rates of high KDPI kidneys, which is estimated to be as high as $50 \%[8,32]$.

Our study showed that procurement biopsies are becoming increasingly common in marginal deceased donors in the United States. Ninety-one percent of KDPI $>85 \%$ kidneys were biopsied on procurement during this study period compared to $85 \%$ between 2000 and 2003 in the United States [33]. The utility of procurement biopsies has been debated as they can delay decisions, require high resources, prolong duration of cold ischemia, and lead to unnecessary kidney discard [21,22]. Furthermore, the reliability of GS degree in predicting graft outcomes has been questioned [8,32]. While several studies have reported increased delayed graft function risk, leading to poor outcomes in kidneys with GS > 20\% [19,25,28,34,35], and other studies have conversely reported similar prognoses in kidneys with GS > 20\% compared to kidneys with lower GS [24,26,27,29]. Banff guidelines for procurement biopsies therefore discourage the use of rigidly defined histologic cutoffs for organ decision and allocation [19].

Using the UNOS database, we demonstrated that GS $>10 \%$ is an independent prognostic factor for graft failure in $>85 \%$ KDPI kidneys, with an adjusted 1.28-fold increased risk of graft failure at 5 years when compared to kidneys with $0-10 \%$ GS. The findings of our study suggest that the use of GS percentage in procurement biopsy of $>85 \%$ KDPI kidneys may improve risk stratification for recipient allograft survival. While GS $>10 \%$ was associated with a higher risk of graft failure in $>85 \%$ KDPI kidneys, we did not find a difference in death-censored graft survival between allografts with $11-20 \%$ GS and $>20 \%$ GS. This may suggest that $>10 \%$ GS in procurement biopsies can potentially be utilized as a cutoff for risk prediction in clinical practice. Given that the presence of GS > 10\% in $>85 \%$ KDPI kidneys had no significant impact on delayed graft function rate, acute rejection, or patient survival, the underlying explanation for higher graft failure in GS > 10\% kidneys is likely due to the progressive kidney aging process in a kidney with less residual function. As the phenotype of GS is associated with podocyte detachment and a reduced number of functioning and viable glomeruli, this leads to increasing ESKD prevalence [36,37]. It has been estimated that an allocation strategy based on pretransplant donor biopsy would increase the incidence of marginal KDPI (80\% to $100 \%)$ renal transplants by over $20 \%$, which would translate into an overall increase of $4 \%$ for the entire pool of donors [38]. Our study supports the clinical utility of the pretransplant biopsy.

This data should not discourage the use of $>85 \%$ KDPI kidneys with $>10 \%$ GS. There is an organ shortage with a growing number of individuals who develop ESKD every year [39] combined with a non-proportional limited supply of potential donors [32]. Overall, one-year post-transplant outcomes have improved since 2007, when the Centers for Medicare and Medicaid Services (CMS) solid organ transplant regulation was first implemented [40]. However, there is still a lack of long term graft and survival outcomes [41-44]. Although transplantation with KDPI > 85\% kidneys might be associated with an increased delayed graft function rate and reduced graft survival [45], it is clearly evident based on the lower mortality rate that recipients benefit from transplantation of high-KDPI kidneys when compared with those who wait for low-KDPI kidneys [46,47]. Thus, instead of discarding $>85 \%$ KDPI kidneys with $>10 \%$ GS due to a higher risk of allograft loss, future studies are needed to identify techniques and strategies to improve the use and outcome of these "marginal" transplantable kidneys safely. Certain strategies are already being used, such as dual transplantation (both kidneys from one donor into the same recipient) [38,48-52] or creation of a protocol designed to timely identify and match suitable patient characteristics with these "marginal" kidneys (e.g., balancing the number of viable nephrons supplied within the graft versus the metabolic demand of the recipient [32]). For example, a $>85 \%$ KDPI kidney with $>10 \%$ GS recovered from a female donor with a low BMI may not be the 
best option for a male candidate with a BMI $>35 \mathrm{~kg} / \mathrm{m}^{2}$ [53]; further studies are needed to identify other patient and donor characteristics that would yield optimal outcomes.

Although our study aimed to assess the impact of GS degree on $>85 \%$ KDPI graft outcomes, the findings of our study cannot be generalized to lower KDPI kidneys. We did compare graft outcomes between KDPI $>85 \%$ kidneys with $0-10 \%$ GS to the overall KDPI 71-85\% kidneys. This demonstrated that graft outcomes of KDPI $>85 \%$ kidneys with 0-10\% GS were inferior to KDPI 71-85\% kidneys, suggesting a stronger impact of KDPI-related factors on graft outcomes over the percentage of GS on procurement biopsies. As KDPI is comprised of several clinically important donor characteristics that impact outcomes [11], it is hypothesized that these characteristics would similarly have an impact on biopsy pathology that is not limited to GS. Thus, GS percentage should not be used in isolation from other biopsy findings for individualized organ acceptance decisions. In addition, the impact GS on graft outcomes of lower KDPI scores remains unclear, since many lower KDPI kidneys are not biopsied [17-19].

Although our study using the UNOS database is among the largest cohorts investigating procurement biopsies with KDPI $>85 \%$, there are some major limitations. First, there is a lack of uniform criteria for procuring, processing and interpreting procurement graft biopsies $[19,54]$. Core needle biopsies (during reperfusion) are usually superior to wedge biopsies (during procurement), as wedge biopsies primarily obtain sub capsular tissue, which can overestimate the amount of GS [24,26,32]. Specimens are frozen sections as opposed to paraffin-embedded tissue obtained for regular kidney biopsies or biopsies at reperfusion [21,32]. Procurement biopsies are also often interpreted by on-call general pathologists rather than nephro-pathologists. Unfortunately, the numbers of glomeruli in samples or type of pathologist were not reported in the registry. Thus, more studies aimed at optimizing assessment of procurement biopsy samples to optimally allocate organs are needed. Second, data on other important biopsy parameters in the UNOS database, such as interstitial fibrosis, tubular atrophy, and arteriosclerosis, were limited. Only 30 patients in our cohort had available reports on the degree of interstitial fibrosis, tubular atrophy, or arteriosclerosis. Therefore, future studies evaluating the predictive role of a complete histological evaluation [55], including glomerular, tubular, interstitial, and vascular compartments of $>85 \%$ KDPI kidneys, are required. Furthermore, GS percentage was reported in the database as $0-10 \%$, $11-20 \%$, and $>20 \%$. Thus, kidney transplant outcomes using a higher cut-off of GS percentage could not be evaluated and required future studies. Furthermore, given the differences between procurement biopsies and reperfusion biopsies [18], the findings of our study cannot be generalized to reperfusion biopsies for $>85 \%$ KDPI kidneys. Finally, the registry may be subjected to selection bias. Kidneys from donors that did not undergo biopsy tended to have less unfavorable clinical characteristics, than those with biopsy as demonstrated in our study (kidney donors in the no biopsy group were younger and had a lower prevalence of diabetes and hypertension), and thus had comparable graft survival rate when compared to the $0-10 \%$ GS group, but superior to the $>10 \%$ GS group. Kidneys with a higher degree of GS were likely to be more carefully selected for unreported factors, including other biopsy characteristics. Alternatively, the kidney discards in each GS percentage cohort may have been impacted by other non-reported factors that influenced study outcomes.

In conclusion, we demonstrated that procurement biopsies for $>85 \%$ KDPI kidneys are very commonly obtained in the United States, at a rate of $91.2 \%$. A higher percentage of GS in $>85 \%$ KDPI kidney biopsies are associated with an increased discard rate. Among KDPI $>85 \%$ kidneys, GS $>10 \%$ is an independent risk factor for allograft failure. However, graft survival from $0-10 \%$ GS kidneys is still inferior to kidneys with KDPI 71-85\%, suggesting a stronger impact of KDPI on graft outcomes. Instead of discarding kidneys, future studies are needed to identify strategies to optimally utilize these "marginal" kidneys safely.

Supplementary Materials: The following are available online at http://www.mdpi.com/2077-0383/9/5/1469/s1, Figure S1: Procurement cohort, Figure S2: Kidney transplant recipient cohort, Table S1: Univariable and multivariable cox regression analyses for post-transplant outcomes between Glomerulosclerosis $>20 \%$ vs. 11-20\%, Table S2: Univariable and multivariable cox regression analyses for post-transplant outcomes between Glomerulosclerosis $>10 \%$ vs. $0-10 \%$. 
Author Contributions: Conceptualization, W.C., C.T., P.K.V., S.K., L.S.C., E.I., J.F. and N.L.; Data curation, W.C. and N.L.; Formal analysis, W.C., A.C. and N.L.; Investigation, W.C., C.T. and N.L.; Methodology, W.C., C.T. and N.L.; Project administration, T.B.; Resources, T.B. and N.L.; Software, N.L.; Supervision, C.T., F.L.K., M.A.M., T.B., S.A.S., S.K., L.S.C., E.I., J.F. and N.L.; Validation, W.C., C.T., A.C., P.H., F.L.K., M.A.M., S.A.S. and N.L.; Visualization, W.C. and C.T.; Writing—original draft, W.C.; Writing—review \& editing, W.C., C.T., P.K.V., A.C., P.H., F.L.K., M.A.M., T.B., S.A.S., S.K., L.S.C., E.I., J.F. and N.L. W.C., C.T., P.K.V., A.C., P.H., F.L.K., M.A.M., T.B., S.A.S., S.K., L.S.C., E.I., J.F. and N.L. All authors have read and agreed to the published version of the manuscript.

Acknowledgments: None. All authors had access to the data and played essential roles in writing of the manuscript.

Conflicts of Interest: The authors declare no conflict of interest.

\section{References}

1. Hart, A.; Smith, J.M.; Skeans, M.A.; Gustafson, S.K.; Wilk, A.R.; Robinson, A.; Wainright, J.L.; Haynes, C.R.; Snyder, J.J.; Kasiske, B.L. OPTN/SRTR 2016 annual data report: Kidney. Am. J. Transp. 2018, 18, 18-113. [CrossRef] [PubMed]

2. Papadopoulos, E.B.; Ladanyi, M.; Emanuel, D.; Mackinnon, S.; Boulad, F.; Carabasi, M.H.; Castro-Malaspina, H.; Childs, B.H.; Gillio, A.P.; Small, T.N.; et al. Infusions of donor leukocytes to treat Epstein-Barr virus-associated lymphoproliferative disorders after allogeneic bone marrow transplantation. N. Engl. J. Med. 1994, 330, 1185-1191. [CrossRef]

3. Gupta, M.; Abt, P.L. Trends among kidney transplant candidates in the United States: Sifting through the tea leaves. Am. J. Transp. 2019, 19, 313-314. [CrossRef] [PubMed]

4. Cecka, J.M. Kidney transplantation in the United States. Clin. Transp. 2008, 1-18.

5. Andre, M.; Huang, E.; Everly, M.; Bunnapradist, S. The UNOS renal transplant registry: Review of the last decade. Clin Transp. 2014, 1-12.

6. Hart, A.; Smith, J.M.; Skeans, M.A.; Gustafson, S.K.; Stewart, D.E.; Cherikh, W.S.; Wainright, J.L.; Kucheryavaya, A.; Woodbury, M.; Snyder, J.J.; et al. OPTN/SRTR 2015 annual data report: Kidney. Am. J. Transp. 2017, 17, 21-116. [CrossRef]

7. United States Renal Data System. 2015 USRDS Annual Data Report: Epidemiology of Kidney Disease in the United States; National Institutes of Health, National Institute of Diabetes and Digestive: Bethesda, MD, USA, 2015.

8. Mohan, S.; Chiles, M.C.; Patzer, R.E.; Pastan, S.O.; Husain, S.A.; Carpenter, D.J.; Dube, G.K.; Crew, R.J.; Ratner, L.E.; Cohen, D.J. Factors leading to the discard of deceased donor kidneys in the United States. Kidney Int. 2018, 94, 187-198. [CrossRef]

9. Lentine, K.L.; Naik, A.S.; Schnitzler, M.A.; Randall, H.; Wellen, J.R.; Kasiske, B.L.; Marklin, G.; Brockmeier, D.; Cooper, M.; Xiao, H.; et al. Variation in use of procurement biopsies and its implications for discard of deceased donor kidneys recovered for transplantation. Am. J. Transp. 2019, 19, 2241-2251. [CrossRef]

10. Metzger, R.A.; Delmonico, F.L.; Feng, S.; Port, F.K.; Wynn, J.J.; Merion, R.M. Expanded criteria donors for kidney transplantation. Am. J. Transp. 2003, 4, 114-125. [CrossRef]

11. Israni, A.K.; Salkowski, N.; Gustafson, S.; Snyder, J.J.; Friedewald, J.J.; Formica, R.N.; Wang, X.; Shteyn, E.; Cherikh, W.; Stewart, D.; et al. New national allocation policy for deceased donor kidneys in the United States and possible effect on patient outcomes. J. Am. Soc. Nephrol. 2014, 25, 1842-1848. [CrossRef]

12. Hart, A.; Smith, J.M.; Skeans, M.A.; Gustafson, S.K.; Wilk, A.R.; Castro, S.; Robinson, A.; Wainright, J.L.; Snyder, J.J.; Kasiske, B.L.; et al. OPTN/SRTR 2017 annual data report: Kidney. Am. J. Transp. 2019, 19, 19-123. [CrossRef] [PubMed]

13. Reese, P.P.; Harhay, M.N.; Abt, P.L.; Levine, M.H.; Halpern, S.D. New solutions to reduce discard of kidneys donated for transplantation. J. Am. Soc. Nephrol. 2016, 27, 973-980. [CrossRef] [PubMed]

14. Bae, S.; Massie, A.B.; Luo, X.; Anjum, S.; Desai, N.M.; Segev, D.L. Changes in discard rate after the introduction of the kidney donor profile index (KDPI). Am. J. Transp. 2016, 16, 2202-2207. [CrossRef] [PubMed]

15. Narvaez, J.R.F.; Nie, J.; Noyes, K.; Leeman, M.; Kayler, L.K. Hard-to-place kidney offers: Donor- and systemlevel predictors of discard. Am. J. Transp. 2018, 18, 2708-2718. [CrossRef]

16. Cohen, J.B.; Shults, J.; Goldberg, D.S.; Abt, P.L.; Sawinski, D.L.; Reese, P.P. Kidney allograft offers: Predictors of turndown and the impact of late organ acceptance on allograft survival. Am. J. Transp. 2018, 18, 391-401. [CrossRef] [PubMed] 
17. Mohan, S.; Campenot, E.; Chiles, M.C.; Santoriello, D.; Bland, E.; Crew, R.J.; Rosenstiel, P.; Dube, G.; Batal, I.; Radhakrishnan, J.; et al. Association between reperfusion renal allograft biopsy findings and transplant outcomes. J. Am. Soc. Nephrol. 2017, 28, 3109-3117. [CrossRef]

18. Carpenter, D.; Husain, S.A.; Brennan, C.; Batal, I.; Hall, I.E.; Santoriello, D.; Rosen, R.; Crew, R.J.; Campenot, E.; Dube, G.K.; et al. Procurement biopsies in the evaluation of deceased donor kidneys. Clin. J. Am. Soc. Nephrol. 2018, 13, 1876-1885. [CrossRef]

19. Liapis, H.; Gaut, J.P.; Klein, C.; Bagnasco, S.; Kraus, E.; Farris, A.B., 3rd; Honsova, E.; Perkowska-Ptasinska, A.; David, D.; Goldberg, J.; et al. Banff histopathological consensus criteria for preimplantation kidney biopsies. Am. J. Transp. 2017, 17, 140-150. [CrossRef]

20. Hall, I.E.; Parikh, C.R.; Schroppel, B.; Weng, F.L.; Jia, Y.; Thiessen-Philbrook, H.; Reese, P.P.; Doshi, M.D. Procurement biopsy findings versus kidney donor risk index for predicting renal allograft survival. Transp. Direct 2018, 4, e373. [CrossRef]

21. Kasiske, B.L.; Stewart, D.E.; Bista, B.R.; Salkowski, N.; Snyder, J.J.; Israni, A.K.; Crary, G.S.; Rosendale, J.D.; Matas, A.J.; Delmonico, F.L. The role of procurement biopsies in acceptance decisions for kidneys retrieved for transplant. Clin. J. Am. Soc. Nephrol. 2014, 9, 562-571. [CrossRef]

22. Stewart, D.E.; Garcia, V.C.; Rosendale, J.D.; Klassen, D.K.; Carrico, B.J. Diagnosing the decades-long rise in the deceased donor kidney discard rate in the United States. Transplantation 2017, 101, 575-587. [CrossRef] [PubMed]

23. Wang, C.J.; Wetmore, J.B.; Crary, G.S.; Kasiske, B.L. The donor kidney biopsy and its implications in predicting graft outcomes: A systematic review. Am. J. Transp. 2015, 15, 1903-1914. [CrossRef]

24. Sung, R.S.; Christensen, L.L.; Leichtman, A.B.; Greenstein, S.M.; Distant, D.A.; Wynn, J.J.; Stegall, M.D.; Delmonico, F.L.; Port, F.K. Determinants of discard of expanded criteria donor kidneys: Impact of biopsy and machine perfusion. Am. J. Transp. 2008, 8, 783-792. [CrossRef] [PubMed]

25. Escofet, X.; Osman, H.; Griffiths, D.F.; Woydag, S.; Adam Jurewicz, W. The presence of glomerular sclerosis at time zero has a significant impact on function after cadaveric renal transplantation. Transplantation 2003, 75, 344-346. [CrossRef] [PubMed]

26. Malek, S.K. Procurement biopsies in kidneys retrieved for transplantation. Clin. J. Am. Soc. Nephrol. 2014, 9 , 443-444. [CrossRef]

27. Bajwa, M.; Cho, Y.W.; Pham, P.T.; Shah, T.; Danovitch, G.; Wilkinson, A.; Bunnapradist, S. Donor biopsy and kidney transplant outcomes: An analysis using the organ procurement and transplantation network/united network for organ sharing (OPTN/UNOS) database. Transplantation 2007, 84, 1399-1405. [CrossRef]

28. Edwards, E.B.; Posner, M.P.; Maluf, D.G.; Kauffman, H.M. Reasons for non-use of recovered kidneys: The effect of donor glomerulosclerosis and creatinine clearance on graft survival. Transplantation 2004, 77, 1411-1415. [CrossRef]

29. Cicciarelli, J.; Cho, Y.; Mateo, R.; El-Shahawy, M.; Iwaki, Y.; Selby, R. Renal biopsy donor group: The influence of glomerulosclerosis on transplant outcomes. Transplant. Proc. 2005, 37, 712-713. [CrossRef]

30. Barlesi, F.; Vansteenkiste, J.; Spigel, D.; Ishii, H.; Garassino, M.; de Marinis, F.; Özgüroğlu, M.; Szczesna, A.; Polychronis, A.; Uslu, R.; et al. Avelumab versus docetaxel in patients with platinum-treated advanced non-small-cell lung cancer (JAVELIN Lung 200): An open-label, randomised, phase 3 study. Lancet Oncol. 2018, 19, 1468-1479. [CrossRef]

31. Hanna, R. Acute kidney injury after pembrolizumab-induced adrenalitis and adrenal insufficiency. Case Rep. Nephrol. Dial. 2018, 8, 238. [CrossRef]

32. Angeletti, A.; Cravedi, P. Making procurement biopsies important again for kidney transplant allocation. Nephron 2019, 142, 34-39. [CrossRef] [PubMed]

33. Cecka, J.M.; Cohen, B.; Rosendale, J.; Smith, M. Could more effective use of kidneys recovered from older deceased donors result in more kidney transplants for older patients? Transplantation 2006, 81, 966-970. [CrossRef] [PubMed]

34. Gaber, L.W.; Moore, L.W.; Alloway, R.R.; Amiri, M.H.; Vera, S.R.; Gaber, A.O. Glomerulosclerosis as a determinant of posttransplant function of older donor renal allografts. Transplantation 1995, 60, 334-339. [CrossRef] [PubMed] 
35. Randhawa, P.S.; Minervini, M.I.; Lombardero, M.; Duquesnoy, R.; Fung, J.; Shapiro, R.; Jordan, M.; Vivas, C.; Scantlebury, V.; Demetris, A. Biopsy of marginal donor kidneys: Correlation of histologic findings with graft dysfunction. Transplantation 2000, 69, 1352-1357. [CrossRef]

36. Hodgin, J.B.; Bitzer, M.; Wickman, L.; Afshinnia, F.; Wang, S.Q.; O'Connor, C.; Yang, Y.; Meadowbrooke, C.; Chowdhury, M.; Kikuchi, M.; et al. Glomerular aging and focal global glomerulosclerosis: A podometric perspective. J. Am. Soc. Nephrol. 2015, 26, 3162-3178. [CrossRef]

37. Rowland, J.; Akbarov, A.; Maan, A.; Eales, J.; Dormer, J.; Tomaszewski, M. Tick-tock chimes the kidney clock-From biology of renal ageing to clinical applications. Kidney Blood Press. Res. 2018, 43, 55-67. [CrossRef]

38. Gandolfini, I.; Buzio, C.; Zanelli, P.; Palmisano, A.; Cremaschi, E.; Vaglio, A.; Piotti, G.; Melfa, L.; La Manna, G.; Feliciangeli, G.; et al. The Kidney Donor Profile Index (KDPI) of marginal donors allocated by standardized pretransplant donor biopsy assessment: Distribution and association with graft outcomes. Am. J. Transp. 2014, 14, 2515-2525. [CrossRef]

39. McCullough, K.P.; Morgenstern, H.; Saran, R.; Herman, W.H.; Robinson, B.M. Projecting ESRD incidence and prevalence in the United States through 2030. J. Am. Soc. Nephrol. 2019, 30, 127-135. [CrossRef]

40. Jay, C.; Schold, J.D. Measuring transplant center performance: The goals are not controversial but the methods and consequences can be. Curr. Transp. 2017, 4, 52-58. [CrossRef]

41. Thongprayoon, C.; Hansrivijit, P.; Leeaphorn, N.; Acharya, P.; Torres-Ortiz, A.; Kaewput, W.; Kovvuru, K.; Kanduri, S.R.; Bathini, T.; Cheungpasitporn, W. Recent advances and clinical outcomes of kidney transplantation. J. Clin. Med. 2020, 9, 1193. [CrossRef]

42. Thongprayoon, C.; Kaewput, W.; Kovvuru, K.; Hansrivijit, P.; Kanduri, S.R.; Bathini, T.; Chewcharat, A.; Leeaphorn, N.; Gonzalez-Suarez, M.L.; Cheungpasitporn, W. Promises of big data and artificial intelligence in nephrology and transplantation. J. Clin. Med. 2020, 9, 1107. [CrossRef] [PubMed]

43. Leeaphorn, N.; Thongprayoon, C.; Chon, W.J.; Cummings, L.S.; Mao, M.A.; Cheungpasitporn, W. Outcomes of kidney retransplantation after graft loss as a result of BK virus nephropathy in the era of newer immunosuppressant agents. Am. J. Transp. 2020, 20, 1334-1340. [CrossRef] [PubMed]

44. Cheungpasitporn, W.; Kremers, W.K.; Lorenz, E.; Amer, H.; Cosio, F.G.; Stegall, M.D.; Gandhi, M.J.; Schinstock, C.A. De novo donor-specific antibody following BK nephropathy: The incidence and association with antibody-mediated rejection. Clin. Transp. 2018, 32, e13194. [CrossRef] [PubMed]

45. Zens, T.J.; Danobeitia, J.S.; Leverson, G.; Chlebeck, P.J.; Zitur, L.J.; Redfield, R.R.; D'Alessandro, A.M.; Odorico, S.; Kaufman, D.B.; Fernandez, L.A. The impact of kidney donor profile index on delayed graft function and transplant outcomes: A single-center analysis. Clin. Transp. 2018, 32, e13190. [CrossRef] [PubMed]

46. Jay, C.L.; Washburn, K.; Dean, P.G.; Helmick, R.A.; Pugh, J.A.; Stegall, M.D. Survival benefit in older patients associated with earlier transplant with high KDPI kidneys. Transplantation 2017, 101, 867-872. [CrossRef]

47. Massie, A.B.; Luo, X.; Chow, E.K.; Alejo, J.L.; Desai, N.M.; Segev, D.L. Survival benefit of primary deceased donor transplantation with high-KDPI kidneys. Am. J. Transp. 2014, 14, 2310-2316. [CrossRef]

48. Ruggenenti, P.; Silvestre, C.; Boschiero, L.; Rota, G.; Furian, L.; Perna, A.; Rossini, G.; Remuzzi, G.; Rigotti, P. Long-term outcome of renal transplantation from octogenarian donors: A multicenter controlled study. Am. J. Transp. 2017, 17, 3159-3171. [CrossRef]

49. Moore, P.S.; Farney, A.C.; Sundberg, A.K.; Rohr, M.S.; Hartmann, E.L.; Iskandar, S.S.; Gautreaux, M.D.; Rogers, J.; Doares, W.; Anderson, T.K.; et al. Dual kidney transplantation: A case-control comparison with single kidney transplantation from standard and expanded criteria donors. Transplantation 2007, 83, 1551-1556. [CrossRef]

50. Gill, J.; Cho, Y.W.; Danovitch, G.M.; Wilkinson, A.; Lipshutz, G.; Pham, P.T.; Gill, J.S.; Shah, T.; Bunnapradist, S. Outcomes of dual adult kidney transplants in the United States: An analysis of the OPTN/UNOS database. Transplantation 2008, 85, 62-68. [CrossRef]

51. Remuzzi, G.; Cravedi, P.; Perna, A.; Dimitrov, B.D.; Turturro, M.; Locatelli, G.; Rigotti, P.; Baldan, N.; Beatini, M.; Valente, U.; et al. Long-term outcome of renal transplantation from older donors. N. Engl. J. Med. 2006, 354, 343-352. [CrossRef]

52. Lee, K.W.; Park, J.B.; Cha, S.R.; Lee, S.H.; Chung, Y.J.; Yoo, H.; Kim, K.; Kim, S.J. Dual kidney transplantation offers a safe and effective way to use kidneys from deceased donors older than 70 years. BMC Nephrol. 2020, 21, 3. [CrossRef] [PubMed] 
53. Foley, D.P.; Sawinski, D. Personalizing donor kidney selection: Choosing the right donor for the right recipient. Clin. J. Am. Soc. Nephrol. 2019, 15, 418-420. [CrossRef] [PubMed]

54. Naesens, M. Zero-time renal transplant biopsies: A comprehensive review. Transplantation 2016, 100, $1425-1439$. [CrossRef] [PubMed]

55. Karpinski, J.; Lajoie, G.; Cattran, D.; Fenton, S.; Zaltzman, J.; Cardella, C.; Cole, E. Outcome of kidney transplantation from high-risk donors is determined by both structure and function. Transplantation 1999, 67, 1162-1167. [CrossRef]

(C) 2020 by the authors. Licensee MDPI, Basel, Switzerland. This article is an open access article distributed under the terms and conditions of the Creative Commons Attribution (CC BY) license (http://creativecommons.org/licenses/by/4.0/). 